\title{
Big Data - Big Chance für Controller?
}

\section{Liebe Leserinnen und Leser,}

Big Data ist in aller Munde. Es klingt wie das Zauberwort für ein erfolgreiches Management in der Cyberwelt. Wer hier zu spät kommt, den bestraft ganz offensichtlich das Leben: Tradierte Geschäftsmodelle fallen den neuen, scheinbar unbegrenzten Möglichkeiten zum Opfer. Derjenige gewinnt, der die scheinbar unendlichen Datenwelten am konsequentesten überschauen und nutzbar machen kann. Schon aus Gründen eines aktiven Risiko-Managements müssten Controller in vorderster Front stehen, um die Möglichkeiten von Big Data für das Unternehmen adäquat zu nutzen.

Nur: Was versteht man eigentlich genau unter „Big Data“? Der Begriff ist auf der einen Seite weit genug, um darunter die unterschiedlichsten Themen subsumieren zu können: Kunden- und Prozessdaten, Suchmaschinen, Predictive Analytics, Social Media, Realtime-Verarbeitung und viele andere mehr. Der Begriff ist auf der anderen Seite intuitiv verständlich. Er hat deshalb ein hohes Potenzial, zum Modewort zu werden - oder ist bereits zu einem solchen geworden. Controller sind also in einer weiteren Funktion gefordert, sich mit Big Data auseinanderzusetzen, nämlich nüchtern die Chancen und Risiken von Themen zu analysieren, die sich hinter Big Data verbergen.

Wie gut fühlen Sie sich darauf vorbereitet? Wie viel wissen Sie über das Thema? Kennen Sie die entsprechenden Aktivitäten in Ihrem Unternehmen, die Big Data zuzuordnen sind? Kennen Sie die relevanten Ansprechpartner? Haben Sie bereits eine Idee, welche Rolle Sie im Zusammenhang mit Big Data spielen wollen? Sehen Sie sich eher als Nutzer für eigene Analysen und Themen, oder glauben Sie, dass Ihre zentrale Funktion - zumindest aktuell - eher darin liegt, den Überblick zu behalten, sicherzustellen, dass das im Unternehmen verstreute Wissen koordiniert wird und damit ein Gesamtbild der Erfahrungen und Einschätzungen entsteht, das den weiteren Weg weist?

Wir glauben, dass Sie als Controller prädestiniert sind, bei Big Data eine aktive, gestaltende Rolle zu spielen. Wer sich Transparenzverantwortung auf die Fahnen geschrieben hat und sich als „single source of truth“ für managementrelevante Informationen sieht, kann an dieser Stelle nicht am Rand stehen und das Spiel andere machen lassen. Die eben gestell-

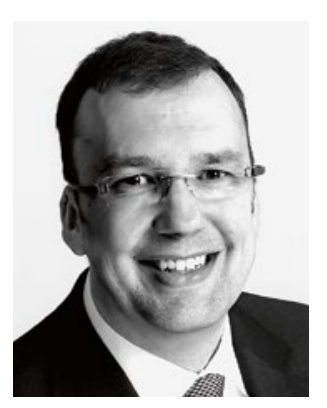

Utz Schäffer

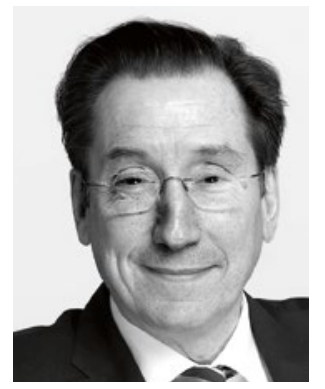

Jürgen Weber ten Fragen sind zugegebenermaßen nicht leicht zu beantworten und bedürfen einer intensiven Auseinandersetzung mit dem Thema. Dies kostet Zeit, die angesichts der stärkeren Rolle des Controllers als Business Partner und angesichts notwendiger Maßnahmen zur Kostenreduzierung im eigenen Bereich derzeit schon mehr als knapp geworden ist. Diese Zeit ist aber gut angelegt. Controller werden nur so die neuen Möglichkeiten von Big Data für eigene Zwecke nutzen können, und nur so werden sie Investitionen in entsprechende IT-Projekte oder neue internetorientierte Geschäftsmodelle kompetent beurteilen können. Nur so werden sie Hilfestellung leisten können, um die entsprechenden Aktivitäten in den unterschiedlichen Unternehmensbereichen miteinander abzustimmen und in ein stimmiges Gesamtkonzept zu überführen. Das Feld ist derzeit noch etwas diffus und die VerheiBung deutlich strahlender als die - immer noch wenigen Beispiele, anhand derer man das Potenzial von Big Data fassbar machen kann. Nicht nur für das Unternehmen, sondern auch für das Controlling ist Big Data aber ein zentrales strategisches Thema, das weder an der Blauäugigkeit des Umgangs damit („strategische Wolken“) noch an der mangelnden Auseinandersetzung damit scheitern sollte.

Viel Spaß bei der Lektüre wünschen Ihnen
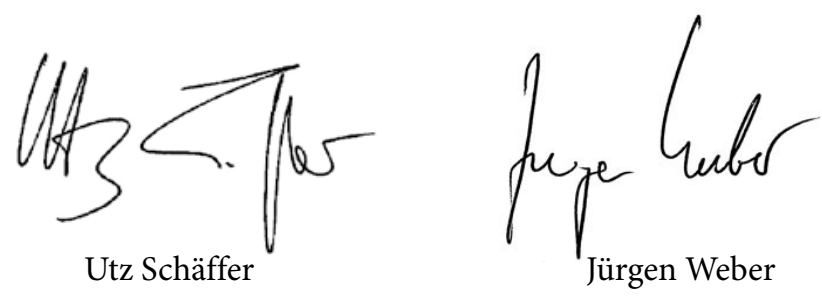